\title{
A rare case of neurofibromatosis with proptosis-orbital neurofibroma
}

\begin{abstract}
D. Divya
Assistant Professor, Dept. of Ophthalmology, Apollo Institute of Medical Sciences and Research, Chittoor, Andhra Pradesh, India

*Corresponding Author:

Email: divyamsophthal@gmail.com

Neurofibromatosis, an oculo--neuro--cutaneous syndrome is characterized by multisystem involvement. A 65 years old male patient came to the dept. of ophthalmology, S. V. R. R. Govt. General Hospital, Tirupati with the complaints of protrusion of his left eye, noticed by him 20 days back, with a history of drooping of left upper eyelid. On physical examination, the patient was short statured (Ht: $148 \mathrm{~cm}$ ) with scoliosis, there were multiple neurofibromas on the skin all over the body and face, freckles in the axillary region and café--au--lait spots over his trunk. On ocular examination, the patient had eccentric proptosis of left eye where the eyeball was shifted downwards (Hypotropia of 450) and forwards (24mm on exophthalmometry) with severe ptosis of left upper eyelid with restriction of extraocular movements. No palpable mass was noted. Finger insinuation between the orbital margin and the globe was possible. Right eye was normal. Slitlamp examination showed multiple Lisch nodules on the surface of iris in both eyes. Fundoscopy showed inferior coloboma choroid of left eye with normal fundus picture in Right eye Binocular diplopia was noted on elevating the upper eyelid of left eye.Forced duction test was positive. CT scan showed proptosis of left eye. Ultrasound B--scan of left eye showed a well defined mass lesion of $1.5 \times 2 \mathrm{~cm}$ size, slightly hyperechoic, with minimal vascularity, situated away from the globe, along the lateral aspect of the orbit suggestive of Orbital neurofibroma. The rare entity in the present case is the Localized form of orbital neurofibroma. Diagnosis in the present case is clinical. Linkage analysis using polymorphic DNA markers can be performed, allowing prenatal diagnosis or presymptomatic diagnosis.
\end{abstract}

Keyword: Oculoneurocutaneous syndrome, Orbital neurofibroma, Lisch nodules.

\section{Background}

Neurofibromatosis, an oculo-neuro-cutaneous syndrome is characterized by multisystem involvement. ${ }^{1}$ Neurofibromatosis type 1 (NF1) affects about 1 in 4000 individuals, and Neurofibromatosis type 2 (NF2) affects about 1 in $50,000 .^{2}$ Both forms are transmitted by an autosomal dominant mode of inheritance. Although the penetrance of both $N F 1$ and NF2 is greater than $95 \%$, the expressivity of the disease is highly variable. ${ }^{1,3}$

Neurofibromatosis type 1, peripheral neurofibromatosis or von Recklinghausen's syndrome, is characterized by cutaneous neurofibromas, café-au-lait spots, Axillary \& inguinal freckles, Lisch nodules of iris, Orbital neurofibromas, optic nerve glioma or solid tumours of central nervous system. ${ }^{4}$ Neurofibromatosis type 2, central or bilateral acoustic neurofibromatosis, is characterized by central neural tumors. Its hallmark is bilateral acoustic neuroma. $^{2}$

Herein we present a case of NF-1 with localized form of orbital neurofibroma, which is a rare presentation constituting only $10 \%{ }^{5}$ of cases, producing the sequelae that mimicks an orbital mass.

\section{Case Presentation}

A 65 years old male patient came to the dept. of ophthalmology, S.V.R.R. Govt. General hospital, Tirupati, with the complaints of protrusion of his left eye, noticed by him 20 days back, with a history of drooping of left upper eyelid. Family history of similar disease was present for his sibling, father and Grandfather.

On physical examination, the patient was short statured (Ht: $148 \mathrm{~cm})$ with scoliosis, there were multiple nodular lesions on the skin all over the body and face, suggestive of neurofibromas(Fig. $1 \& 2$ ), there were freckles in the axillary region and café-au-lait spots over his trunk.

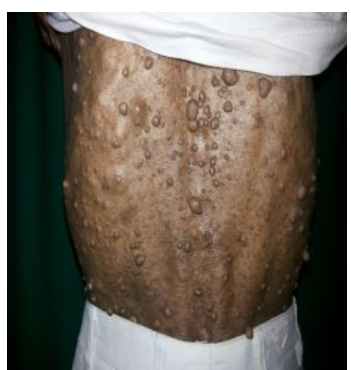

Fig. 1: Cutaneous neurofibromas

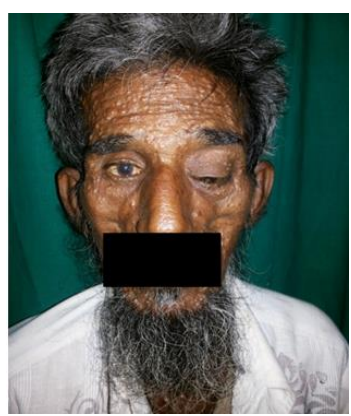

Fig. 2: Neurofibromas over face and severe ptosis of left eyelid

On ocular examination, the patient had eccentric proptosis of left eye where the eyeball was shifted downwards (Hypotropia of $45^{\circ}$ ) and forwards $(24 \mathrm{~mm}$ on exophthalmometry) (Fig. 4) with severe ptosis of left upper eyelid (Fig. 2) with restriction of extraocular 
movements (Fig. 5). No palpable mass was noted. Finger insinuation between the orbital margin and the globe was possible. Right eye was normal. Slit lamp examination showed multiple Lisch nodules on the surface of iris in both eyes (Fig. 6). Fundoscopy

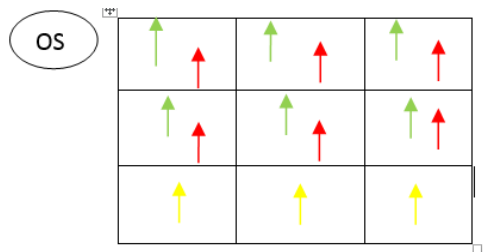

Fig. 3: Binocular Diplopia on upgaze
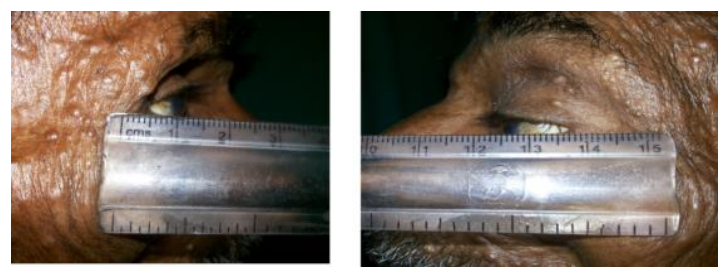

Fig. 4: Proptosis of Left eye
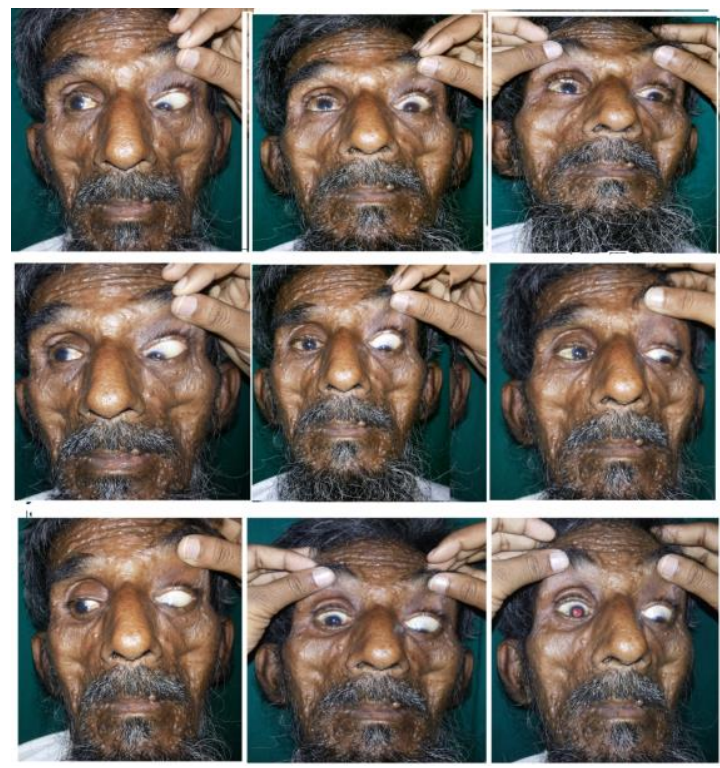

Fig. 5: Restriction of extraocular movements in left eye except for depression, dextro-depression and levodepression showed inferior coloboma choroid of left eye with normal fundus picture in Right eye (Fig. 7). Binocular diplopia was noted on elevating the upper eyelid of left eye (Fig. 3). Forced duction test was positive.
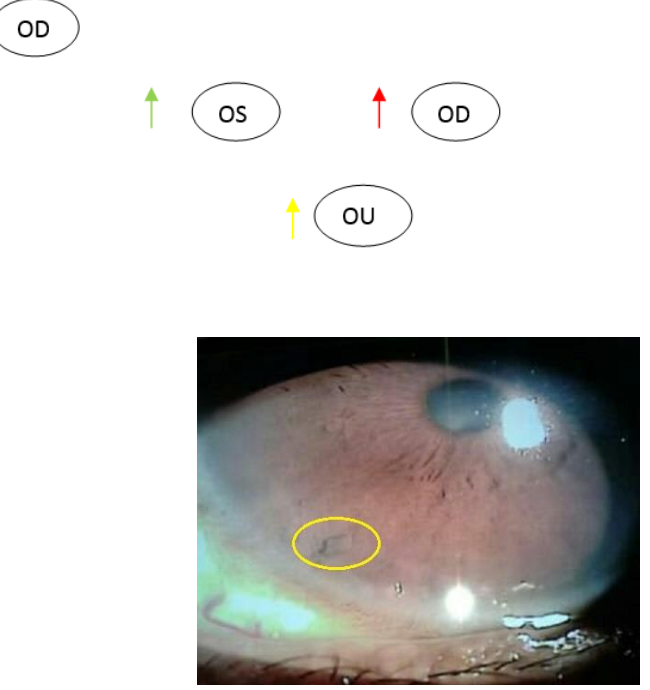

Fig. 6: Lisch Nodule over the surface of Iris

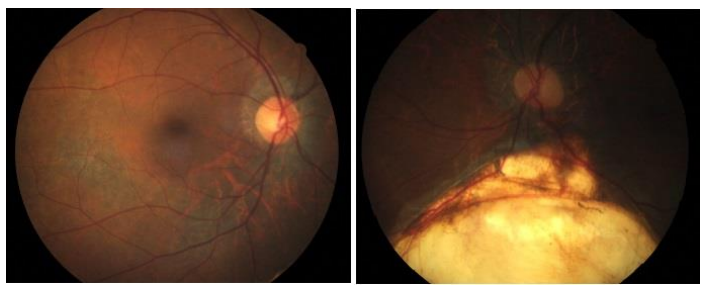

Fig. 7: Fundus picture-Right eye-Normal; Left eyeInferior coloboma choroid

CT scan showed proptosis of left eye with a well defined mass lesion of $1.5 \times 1 \mathrm{~cm}$ size, isodense with brain parenchyma, located in the extraconal space along the posterolateral aspect of the orbit. No bony erosion was noted (Fig. 8). Ultrasound B-scan of left eye showed a well defined mass lesion of $1.5 \times 2 \mathrm{~cm}$ size, slightly hyperechoic, with minimal vascularity, situated away from the globe, along the lateral aspect of the orbit (Fig. 9).

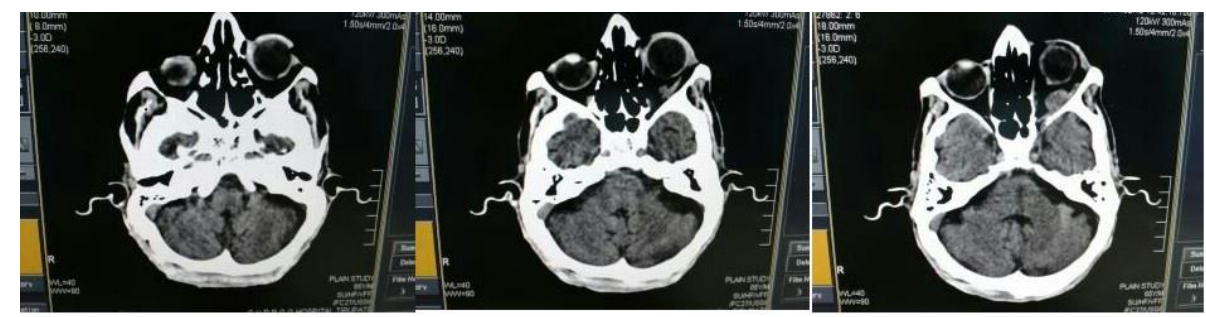

Fig. 8: CT scan showing mass lesion extraconally in postero-lateral aspect of the orbit 


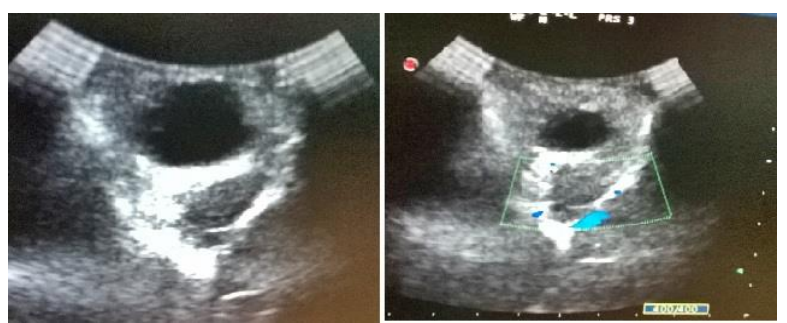

Fig. 9: Ultrasound B-scan of Left eye showing mass lesion and colour doppler showing minimal vascularity

\section{Discussion}

The neurofibromatosis are a group of autosomaldominant disorders, characterized by genetically distinct neurocristopathies (multiple hamartomas of neural crest origin) in which individuals develop both benign and malignant tumors at an increased frequency. ${ }^{6-8}$ The NF 1 gene is on the long arm of chromosome 17. It has been cloned and its protein product, neurofibromin, was identified in $1990 . .^{9-11}$ The hallmark of the NF 1 gene is its high mutation rate re $^{12}$ with up to $50 \%$ of cases being caused by de novo mutations.

The diagnosis of NF 1 is based primarily on clinical criteria. The diagnostic criteria for NF1 as originally established by the NIH Consensus Development Conference specified that two or more of the following be present: (1) six or more cafe-au-lait macules more than $5 \mathrm{~mm}$ in greatest diameter in prepubertal individuals and more than $15 \mathrm{~mm}$ in greatest diameter after puberty, (2) two or more neurofibromas of any type or one plexiform neurofibroma, (3) freckling in the axillary or inguinal regions, (4) optic glioma, (5) two or more Lisch nodules (iris hamartomas), (6) an osseous lesion, such as sphenoid wing dysplasia or thinning of the cortex of the long bones(with or without pseudoarthrosis), and (7) a firstdegree relative with NF 1 by the above criteria. ${ }^{13}$

Our present case satisfies 5 of the above mentioned criteria confirming the diagnosis as NF-1. The rare entity in the present case is the Localized form of orbital neurofibroma.

Orbital Neurofibroma is probably the most frequent peripheral nerve tumor of the orbit, accounting for 0.8 to $3.0 \%$ of all histopathologically proven orbital lesions. ${ }^{14-16}$ It is classified into three subsets: Plexiform, Diffuse, and Localized. The localized type is only seldom associated with neurofibromatosis. ${ }^{17,5}$ It behaves like many other solitary well-circumscribed soft tissue tumors in the orbit and presents at a later age than the plexiform type. The typical patient is a young or middle-aged adult. ${ }^{18,19}$ Clinical features include proptosis and downward displacement of the globe owing to the preferential location of the tumor in the superior orbit. ${ }^{18,24}$ The inferior orbit can also be affected. ${ }^{19}$ Isolated neurofibroma can occur in the lacrimal gland region, simulating a lacrimal gland tumor. ${ }^{20}$ It can also develop in an extraocular muscle. ${ }^{21}$

In localized neurofibromas, orbital CT reveals a well circumscribed ovoid mass generally in the superior orbit and less commonly in the inferior orbit. The tumor generally occupies an extraconal position and does not involve the orbital apex. Localized neurofibroma can demonstrate extension into the superior orbital fissure in $33 \%$ of the cases. ${ }^{22}$

On gross examination, the localized orbital neurofibroma appears as a well-defined yellow or white lesion in contrast to the other 2 forms. The lesion usually has a capsule. The surgical specimen of an isolated orbital neurofibroma often includes a piece of the nerve from which the tumor arises in $63 \%$ of neurofibromas. ${ }^{22}$ Microscopically, localized neurofibromas are composed of interwoven bundles of axons, Schwann cells, and endoneural fibroblasts within a mucoid matrix. ${ }^{23}$

Diagnosis in the present case is clinical. Linkage analysis using polymorphic DNA markers can be performed, allowing prenatal diagnosis or presymptomatic diagnosis. Additionally, a commercial assay for NF1 gene mutations is available that is based upon a protein truncation test, ${ }^{25}$ with limited sensitivity (60\%-70\%), however, and is not yet recommended as the single diagnostic tool for NF1; rather, it can be used in conjunction with the clinical findings.

The management of localized orbital neurofibroma consists of total excision. Postoperatively, a sensory skin deficit was present in $72 \%$ of the patients with an isolated orbital neurofibroma. $46 \%$ of tumors can usually be dissected completely from the surrounding orbital contents. Incompletely excised tumors are not at particular risk for recurrence in contrast to the other 2 types. $^{22}$

Funding: No funding sources.

Conflict of interest: None declared.

\section{References}

1. Sippel KC. Ocular findings in neurofibromatosis type 1 . Int Ophthalmol Clin 2001;41:25-40.

2. The National Institutes of Health Consensus Development Conference. Neurofibromatosis. Arch Neurol 1988;45:575-78.

3. Rettele GA, Brodsky MC, Merin LM, et al. Blindness, deafness,quadriparesis and a retinal malformation: The ravages of neurofibromatosis 2. Surv Ophthalmol 1996;41:135-41.

4. Riccardi V M.Neurofibromatosis:Past, present and future. N Engl J Med 1991;324:283-85.

5. Zia Chaudhuri,MVanathi: Post graduate Ophthalmology. $1^{\text {st }}$ edition. 2012;2:1891-92.

6. Huson SM, Compston DAS, Clark P, et al: A genetic study of vonRecklinghausen neurofibromatosis in south east Wales. Prevalence, fitness, mutation rate, and effect of parental transmission on severity. J Med Genet 1989;26:704-11.

7. Riccardi VM: Neurofibromatosis: Past, present, and future. N Engl J Med 1991;324:1283-85. 
8. Riccardi VM, Eichner JE: Neurofibromatosis: Phenotype, natural history and pathogenesis, ed 2. Baltimore, Johns Hopkins University Press, 1992

9. Cawthon RM, Weiss M, Xu G, et al: A major segment of the neurofibromatosis Type I gene: cDNA sequence, genomic structure, and point mutations. Cell 1990;62:193-201.

10. Van der Hoev J: Les phacomatoses de Burneville, de Recklinghausen et de von Hippel-Lindau. J Belgian Neurol Psychiatry 1933;33:752-62.

11. Weiss DI:Dial origin of glaucoma in encephalotrigeminal haemangiomatosis: A pathogenetic concept based upon histopathologic and haemodynamic consideratons. Trans Am Ophthalmol SOC 1973;93:477493.

12. Huson SM, Hughes RAC: The Neurofibromatoses: A Pathogenetic and Clinical Overview. London, Chapman and Hall, 1994.

13. Neurofibromatosis conference statement. National Institutes of Health Consensus Development Conference. Arch Neurol 1988;45(5):575-78.

14. Shields JA, Bakewell B, Augsburger JJ, Flanagan JC. Classification and incidence of space-occupying lesions of the orbit. Arch Ophthalmol 1984;102:1606-611.

15. Henderson JW, Campbell RJ, Farrow GM, Garrity JA. Orbital Tumors. New York: Raven Press; 1994:43-52.

16. Sen DK. Aetiological pattern of orbital tumors in India and their clinical presentations. A 20-year retrospective study. Orbit 1990;9:299-302.
17. Shields JA. Diagnosis and Management of Orbital Tumors.Philadelphia: WB Saunders; 1989:149-169

18. Krohel GB, Rosenberg PN, Wright JE, Smith RS. Localized orbital neurofibromas. Am J Ophthalmol 1985;100:458-64.

19. Rocca RCD, Roen J, Labay GR, Bedrossian E. Isolated neurofibroma of the orbit. Ophthalmic Surg 1985;16:634-638.

20. McDonald P, Jakobiec FA, Hornblass A, Iwamoto T. Benign peripheral nerve sheath tumors (neurofibromas) of the lacrimal gland. Ophthalmol 1983;90:1403-13.

21. Abe T, Kawamura N, Homma H, et al. MRI of orbital schwannomas. Head Neck Radiol 2000;42:466-468

22. Rose GE, Wright JE. Isolated peripheral nerve sheath tumours of the orbit. Eye 1991;5:668-73.

23. Henderson JW, Campbell RJ, Farrow GM, Garrity JA. Orbital Tumors. New York: Raven Press; 1994:221-37.

24. American Cancer Society Atlas of Clinical Oncology Tumors of the Eye and Ocular Adnexa Devron H. Char, MD, 2001:CHAPTER 17:350

25. Heim RA, Silverman LM, Farger RA, et al: Screening for truncated NFl proteins. Nat Genet 1994;8:218-19.

How to cite the article: D. Divya. A rare case of neurofibromatosis with proptosis-orbital neurofibroma. Int J Ocul Oncol Oculoplasty 2018;4(3):140-143. 